\title{
Effectiveness of Health Teaching Program about the Knowledge of Tobacco Use IIl-Effects among High School Students
}

\author{
Muhammad Muneeb Ullah Saif ${ }^{1}$ Muhammad Afzal ${ }^{2} \quad$ Muhammad Hussain $^{3}$ Iram Majeed $^{4}$ Kausar Parveen $^{4}$ \\ Syed Amir Gilani ${ }^{5}$ \\ 1. BS Nursing, Lahore School of Nursing, The University of Lahore, PO box 54000, Lahore, Pakistan \\ 2. Associate Professor, Lahore School of Nursing, the University of Lahore, PO box 54000, Lahore, Pakistan \\ 3. Assistant Professor, Lahore School of Nursing, the University of Lahore, PO box 54000, Lahore, Pakistan \\ 4. Nursing Instructor, Lahore School of Nursing, the University of Lahore, PO box 54000, Lahore, Pakistan \\ 5. Professor, FAHS the University of Lahore, PO box 54000, Lahore, Pakistan.
}

\begin{abstract}
Introduction: Tobacco use is a major factor for non-communicable diseases like cerebrovascular accidents, acute coronary syndrome, hypertension, debilitating chronic diseases like atherosclerosis and chronic obstructive pulmonary disease. Tobacco use is a bad habit that starts before the accomplishment of adulthood, and young people, specifically, are more in prone to create nicotine addiction. Nursing faculty can also teach and advice all students to change their state of mind in regards to tobacco utilization and help them to quit the use tobacco. Methods: Quasi experimental study performed on 54 male high school students to evaluate the effectiveness of health teaching session about the knowledge of tobacco use ill-effects. Results: Findings revealed that the mean post-test mean score was significantly higher than their mean pre-test score. The calculated " $\mathrm{t}$ " value $(\mathrm{t}=-88.520$ $\mathrm{p}<0.005$ ) was greater than the table value at 0.05 in all sections. Therefore, the null hypothesis Conclusions: It is concluded that the educational program is effective in enhancing the knowledge of students regarding ill- effects of tobacco use.
\end{abstract}

Keywords-, Health Teaching Program, Knowledge, and Tobacco use ill-effects.

DOI: $10.7176 / \mathrm{JHMN} / 67-10$

Publication date:October $31^{\text {st }} 2019$

\section{INTRODUCTION}

The action of breathing in and breathing out smoke of burning tobacco in cigars, cigarette and funnel is called cigarette smoking or smoking. Initially it was begun by Native Americans and it was common in customs and for restorative procedures. Tobacco use spread slowly everywhere throughout the world by the end of $19^{\text {th }}$ century. Allender's work (Gholap, 2015).

Tobacco use is a major factor for non-communicable diseases like Cerebrovascular Accidents, Acute Coronary Syndrome, hypertension, debilitating chronic diseases like atherosclerosis and Chronic Obstructive Pulmonary Disease (WHO, 2017). It is a main source of malignancies comprises tumour of lungs, mouth cavity, larynx and pancreas (Bartwal, Awasthi, Rawat, \& Arya, 2014).

Impacts of tobacco utilize contain respiratory issues, nicotine dependence and addiction to the others drugs. The carbon monoxide in tobacco smoke decreases the oxygen level in blood. Absence of Oxygen in blood at that point influences the working of body part or organs such as lungs, heart and brain (Solomon, Wu, \& Gillam, 2017).

Tobacco utilize has many extreme effects on our body, mental, and financial terrible impacts. Between adolescence, students are especially prone to smoking because of educational burdens and other life related tensions (M. M. Kumar \& Nageshwar, 2018).

There are 21 disease that spread due to smoking, 12 different kinds of cancers, , diabetes, chronic obstructive pulmonary disease (COPD), pneumonia and 6 classification of cardiovascular disease (Siegel, Miller, \& Jemal, 2017). Tobacco utilizes is related with expanded hazards of cardiovascular and chronic respiratory diseases, stroke, and cancers of numerous organs of the body such as mouth, larynx, lungs, kidneys, cervix, and pancreas (Bartwal et al., 2014).

As indicated by WHO 6 million peoples die due to tobacco smoking and an expected 600,000 peoples lose their lives because of second hand smoking all around the world every year (Organization, 2015). Tobacco utilizes is related to significantly high rate of mortality, representing around 2 million expiries in people aged $\geq 45$ in one year in all over the Asia. It is likely that tobacco utilize related expiries in Asia will keep on increase in future if no tobacco control programs will apply (Zheng et al., 2014)

Tobacco use is a bad habit that starts before the accomplishment of adulthood, and young people, specifically, are more in prone to create nicotine addiction. This is huge distress for nations like Pakistan, where tobacco utilization is intensely increasing among youths (Rao, Aslam, Zaheer, \& Shafique, 2014). 
Different variables impact tobacco use among youthful students. Dependence on tobacco items and other substance of abuse among relatives and companion gatherings, family clashes, weak school performance, absenteeism and school failures has been observed to be related with smoking at an early age (Bagchi, Ganguly, Pal, \& Chatterjee, 2014)

In Pakistan, youths were estimated to be the weakest people to pick up practice of tobacco use, $9-14 \%$ of school kids were habitually involved in this bad habit (Shah \& Siddiqui, 2015). Among the age group of 1319 years, a person is most likely to get involved in smoking habit and become an addict for the rest of his or her life. This age characterizes as the growth of maturity where teens make decision for their life and plan where they want to see themselves in the upcoming life (Mohanan, Swain, Sanah, Sharma, \& Ghosh, 2014).

\section{LITERATURE REVIEW}

According to WHO Tobacco use is related to about $20 \%$ adult mortality around the world. It is estimated that tobacco use will cause the death of 8 million people every year by 2030 and $80 \%$ of these deaths will occur in low and middle income countries. It is estimates that about $21 \%$ of Pakistan's population smoked (approximately 23,652,300 persons). If tobacco control efforts continue at the same intensity, WHO projects that in 2025 around $24 \%$ of the population (approximately 36,724,600 persons) will be smokers (WHO, 2015).

According to Adult tobacco survey 2014 in Pakistan showed that $19.1 \%$ adults were currently using tobacco products and among them, $12.4 \%$ smoked tobacco, and 7.7\% smokeless tobacco. Exposure to second hand smoke was seen in $86 \%$ in a restaurant while it was $76 \%$ on public transportation (Saqib et al., 2017).

In 2014 Surgeon General's report estimates that cigarette smoking causes more than 480,000 deaths each year in the United States. Study concluded, that cause-specific mortality in a large population identified associations between smoking and increased mortality from several diseases that are not currently established as caused by smoking. Results suggest that the number of persons in the United States who die each year as a result of smoking cigarettes may be greater than currently estimated (Health \& Services, 2014).

According to WHO Tobacco smoking is the leading cause of preventable disease and death in the United States, resulting in approximately 480,000 premature deaths and more than $\$ 300$ billion in direct health care expenditures and productivity losses each year (WHO, 2015).

A study conducted to evaluate the smoking and associated psychosocial factors among adolescent students, gave results as the prevalence of smoking was found 37\% among males and 13.5\% among females, with overall prevalence was $29.6 \%$. Smoking by father and peer group and conflict among parents were positively associated with smoking by students (Bagchi et al., 2014).

A research conducted to assess the various reasons for smoking among teenagers of age 14-17 years. Results showed that majority of $76.4 \%$ of the study subjects agreed that smoking habit gives psychological pleasure, $77.5 \%$ agreed that smoking starts because of friends, and $65.7 \%$ felt that smoking starts as an inspiration for outlook and personality. Study concluded that, there are various psychological factors, personal factors, and social factors are attached with smoking habit (Anjum et al., 2016).

This study conducted to find the demographic and socioeconomic correlates of hookah use among high school seniors in the United States, gave the result as adolescents of higher socioeconomic status appear to be at particularly high risk for hookah use in the United States (Palamar, Zhou, Sherman, \& Weitzman, 2014).

According to a survey regarding knowledge of harmful effect of smoking among the adult in the rural area less than half (39.6\%) of the Adults had average knowledge, more than half $(54.4 \%)$ of the Adults had low knowledge and no any person had the high level of knowledge (Gholap, 2015).

Noreen Shah and Saad Siddiqui conducted a research with the aim to assess smoking practices across Pakistan. Result of study shows that majority of studies reported adolescence as time of initiation. Average national prevalence was $21.6 \%$. A significant portion of smokers comprised of females. The prevalence of smoking in healthcare professionals ranged from $32-37 \%$. Passive smoking was a major contributor of tobacco exposure. Study concluded that smoking continues to be a major public health issue in Pakistan. The prevalence in healthcare professionals and adolescents is alarming (Shah \& Siddiqui, 2015). 


\section{METHODOLOGY}

Setting: The research was conducted Govt. High School for Boys, Ali Raza Abad Lahore-Pakistan. Research design: Quasi experimental design was use in this study. Population: All students of $9^{\text {th }}$ and $10^{\text {th }}$ classes in High School Ali Raza Abad were the target population of this study. Sampling: Convenient sampling technique used for the selection of subjects. Research instrument: Questionnaire: which contains two parts, first part demographic data and the second part contain questions related knowledge regarding tobacco use ill-effects. Data Gathering Procedure: The data collected through structured questionnaire. The pre data collected through questionnaires were saved as baseline and then, health teaching program conducted in classes at Govt. High School Ali Raza Abad. The interventions were done in four weeks. After that, post data collected again from students regarding tobacco use ill-effects.

\section{RESULTS}

This section presents the outcomes of the study, Profile of the respondents and outcome of questionnaire regarding knowledge of tobacco use ill-effects and also represents the result of paired t-test comparison before and after intervention and results for objective of this study "To evaluate the Effectiveness of health teaching program about the knowledge of tobacco use ill-effects among high school students.

\begin{tabular}{|c|c|c|c|}
\hline \multicolumn{4}{|c|}{ Table No:1 } \\
\hline S\# & Demographic Characteristic & $\mathbf{N}$ & $\%$ \\
\hline & & 54 & $100 \%$ \\
\hline 1 & Q:Occupation of parents & & \\
\hline & Service in private sector & 14 & $25.92 \%$ \\
\hline & Service in government sector & 15 & $27.77 \%$ \\
\hline & Business & 17 & $31.48 \%$ \\
\hline & Agriculture & 08 & $14,81 \%$ \\
\hline 2 & Q: History of Tobacco use in Family & & \\
\hline & Yes & 16 & $29.1 \%$ \\
\hline & No & 36 & $69.1 \%$ \\
\hline 3 & Q: Recreational facility at home & & \\
\hline & Television & 33 & $60 \%$ \\
\hline & Magazines and newspapers & 04 & $07 \%$ \\
\hline & Internet & 06 & $10 \%$ \\
\hline & Play with peers & 11 & $20 \%$ \\
\hline 4 & Q: Previous knowledge regarding the ill-effects of tobacco & & \\
\hline & Yes & 13 & $23.3 \%$ \\
\hline & No & 41 & $74.7 \%$ \\
\hline
\end{tabular}

According to this table total of 54 respondents participated in the study it also represents the demographic characteristics of participants this table this shows that about $31.48 \%$ of parents have their own business, $69.1 \%$ have no history of tobacco use in their family $60 \%$ have television as recreational facility at home and $74.7 \%$ have Previous knowledge regarding the ill-effects of tobacco.

\begin{tabular}{|c|c|c|c|c|c|}
\hline \multicolumn{6}{|c|}{ Table No: 2 Mean Percentages } \\
\hline & Mean & Mean\% & SD & SE & $\mathbf{N}$ \\
\hline Knowledge score Pre intervention & 14.37 & $41.05 \%$ & 2.72 & .37 & 54 \\
\hline Knowledge score Post intervention & 28.15 & $80.00 \%$ & 14.80 & 2.01 & 54 \\
\hline
\end{tabular}

Following table shows the mean, standard deviation, standard error of mean and mean percentages of pre-post score of knowledge and practice, illustrate that the knowledge and practice score mean improved in post intervention phase. That was 14.37 pretest knowledge and improved at 28.15 level in post intervention phase, similarly the practice mean also improved from $41.05 \%$ to $80.00 \%$ in post test phase. 


\begin{tabular}{|l|l|l|l|l|}
\hline \multicolumn{5}{|c|}{ Table No: 3 Knowledge ill effects of Tabaco use by respondents } \\
\hline Variables & $\begin{array}{l}\text { Knowledge } \\
\text { pre-intervention }\end{array}$ & $\begin{array}{l}\text { Knowledge } \\
\text { post-intervention }\end{array}$ \\
\hline & $\mathrm{N}$ & $\mathbf{\%}$ & $\mathrm{N}$ & $\mathbf{\%}$ \\
\hline The age when tobacco use usually begins is around 10years. & $\mathbf{0 5}$ & $\mathbf{9 . 2 5} \%$ & $\mathbf{3 4}$ & $\mathbf{6 2 . 9 6 \%}$ \\
\hline Tobacco use in adolescence is influenced by peer group. & $\mathbf{3 9}$ & $\mathbf{7 2 . 2 2 \%}$ & $\mathbf{4 9}$ & $\mathbf{9 0 . 7 4 \%}$ \\
\hline $\begin{array}{l}\text { Smoking variety and smokeless variety are two types of } \\
\text { tobacco use. }\end{array}$ & $\mathbf{1 3}$ & $\mathbf{2 4 . 0 7 \%}$ & $\mathbf{1 5}$ & $\mathbf{2 7 . 7 7 \%}$ \\
\hline Zarda, gutkha and snuff are the examples of smoking variety. & $\mathbf{2 2}$ & $\mathbf{4 0 . 7 4 \%}$ & $\mathbf{2 9}$ & $\mathbf{5 3 . 7 0 \%}$ \\
\hline One cigarette/beedi reduces seven minutes of your life. & $\mathbf{0 6}$ & $\mathbf{1 1 . 1 1 \%}$ & $\mathbf{4 1}$ & $\mathbf{7 5 . 9 2 \%}$ \\
\hline Giving up tobacco use improves self-confidence. & $\mathbf{3 1}$ & $\mathbf{5 7 . 4 0 \%}$ & $\mathbf{4 7}$ & $\mathbf{8 7 . 0 3 \%}$ \\
\hline
\end{tabular}

Paired Samples Test

\begin{tabular}{|c|c|c|c|c|c|c|c|c|c|}
\hline & & \multicolumn{5}{|c|}{ Paired Differences } & \multirow[t]{3}{*}{$\mathrm{t}$} & \multirow[t]{3}{*}{$\mathrm{df}$} & \multirow{3}{*}{$\begin{array}{l}\text { Sig. (2- } \\
\text { tailed) }\end{array}$} \\
\hline & & \multirow[t]{2}{*}{ Mean } & \multirow[t]{2}{*}{$\begin{array}{c}\text { Std. } \\
\text { Deviation }\end{array}$} & \multirow[t]{2}{*}{$\begin{array}{l}\text { Std. } \\
\text { Error } \\
\text { Mean }\end{array}$} & \multicolumn{2}{|c|}{$\begin{array}{c}95 \% \text { Confidence } \\
\text { Interval of the } \\
\text { Difference }\end{array}$} & & & \\
\hline & & & & & Lower & Upper & & & \\
\hline $\begin{array}{l}\text { Pair } \\
1\end{array}$ & $\begin{array}{l}\text { Pre-Test - } \\
\text { Post-Test }\end{array}$ & -13.778 & 1.144 & .156 & -14.090 & -13.466 & -88.520 & 53 & .000 \\
\hline
\end{tabular}

Findings revealed that the mean post-test mean score was significantly higher than their mean pre-test score. The calculated " $\mathrm{t}$ " value $(\mathrm{t}=-88.520 \mathrm{p}<0.005)$ was greater than the table value at 0.05 in all sections. Testing Hypothesis: As the calculated " $t$ " value was greater than the table value at 0.05 in all sections. Therefore, the null hypothesis (H0: There is no effectiveness of health teaching program about the knowledge of tobacco use illeffects among high school students) was rejected and alternate research hypothesis $\left(\mathbf{H}_{1}\right.$ : There is effectiveness of health teaching program about the knowledge of tobacco use ill-effects among high school students) was accepted. Hence it is concluded that there is significant gain in knowledge of students through health teaching program on tobacco use ill-effects.

\begin{tabular}{|c|c|c|c|c|c|c|}
\hline \multicolumn{7}{|c|}{ Tests of Normality } \\
\hline & \multicolumn{3}{|c|}{ Kolmogorov-Smirnov ${ }^{\mathrm{a}}$} & \multicolumn{3}{|l|}{ Shapiro-Wilk } \\
\hline & Statistic & df & Sig. & Statistic & $\mathrm{df}$ & Sig. \\
\hline Pre & .074 & 52 & $.200^{*}$ & .990 & 52 & .950 \\
\hline Post & .079 & 52 & $.200^{*}$ & .985 & 52 & .729 \\
\hline
\end{tabular}

Following table showed that according to Shapiro-wilk's test the $(\mathrm{p}>.05)$ and the visual inspection of histogram, normal Q-Q plots and box plot showed that the score of knowledge and practice in pre and post phase were normally distributed.

\section{DISCUSSION}

The role of nursing professionals is vital in giving health teaching and creating awareness among the community. The nurse must deliver health teaching in schools and colleges for the students. They need to be facilitated to breakdown the chain of shame and improve awareness among themselves and give importance to their health. The present study was conducted to evaluate the effectiveness of health teaching program on ill- 
effects of tobacco among high school students with a purpose to develop their knowledge about the ill-effects of tobacco use. The findings of the study are discussed as following.

Description of demographic variables of the student: Majority (70\%) of the students had no family history of smoking and tobacco use and only (30\%) of the sample have family history of smoking or tobacco use. The analysed data regarding recreational facility of the students reveals that highest percentage (61\%) of the students were using TV, $7 \%$ had magazines, $11 \%$ had internet and $21 \%$ were playing with peers.

Similar findings were found in another study among13-15years of students and the result revealed that current tobacco users $(90.4 \%)$ were likely to watch actors chewing tobacco on TV, video, or movies (Sinha, 2005).

In contrast, demographic variable related findings of a previous study shows that $40 \%$ of the respondents have no history of smoking in their family and $60 \%$ of the respondents got the information regarding ill effects of smoking through newspaper/magazines (Tuppad, 2017).

Analysis of the pre-test knowledge of the students regarding ill-effects of tobacco use: Item-wise analysis of the correct responses regarding ill-effects of tobacco use revealed that the majority of students had weak knowledge related to following items, only $5(9 \%)$ students gave the right answer to the item that age when tobacco use usually begins is around 10 years, 11 students gave the right answer to the question that children of tobacco users rarely follow their parents in their habits and only 6 students knew that one cigarette/beedi reduces seven minutes of your life. Present study shows that the overall mean percentage knowledge score in the pre-test was $41 \%$ which shows lack knowledge regarding ill effects of smoking in high school students. The findings of the study was similar that the overall mean percentage knowledge score in the pre-test was $33.8 \%$ which shows lack knowledge regarding ill effects of smoking in high school students (Tuppad, 2017).

Present study shows that $37(65 \%)$ students knew that tobacco use can lead to oral cancer and lung cancer. In contrast the findings of a study shows that all students (100\%) knew that smoking is injurious to health and cancer was caused by tobacco consumption (Singh \& Gupta, 2006).

Effectiveness of health teaching program and testing hypothesis: Findings of present study reveals that highest effectiveness $(10 \%$ to $71 \%$ ) was observed for the item "One cigarette/beedi reduces seven minutes of your life. Overall mean score in pre-test was 14.37 and in post-test overall mean score was 28.15 and the mean difference between pre-test score and post test score was 13.77. Findings revealed that the mean post-test mean score was significantly higher than their mean pre-test score. The calculated " $\mathrm{t}$ " value $(\mathrm{t}=-88.520 \mathrm{p}<0.005)$ was greater than the table value at 0.05 in all sections. Overall mean percentage of knowledge score in the pre-test was $41 \%$ and after health teaching interventions overall mean percentage of knowledge score in the post-test was $80.4 \%$.

A similar study shows that the overall mean percentage knowledge score in the pre-test was $33.8 \%$ and $69.28 \%$ in the post test. The overall findings of the study clearly showed that the educational program against tobacco was significantly effective in improving the knowledge scores of high school students regarding ill effects of smoking (Tuppad, 2017).

Another similar study analysed the results of pre-test and post-test knowledge score using paired t-test which revealed that there was significant improvement $(t=27.61, p=0.001)$ in knowledge regarding harmful effects of alcohol and tobacco use (B. Kumar, Prakash, Prakash, \& Muthuvenkatacha1lam, 2013).

\section{CONCLUSION}

Overall mean percentage knowledge score in the pre-test was $41 \%$ which shows lack knowledge regarding ill effects of smoking in high school students, after health teaching interventions overall mean percentage of knowledge score in the post-test was $80.4 \%$. Mean post-test score was significantly higher than their mean pre-test score. Hence Study concluded that the health teaching program against tobacco was significantly effective in improving the knowledge of high school students regarding ill effects of smoking.

\section{ACKNOWLEDGEMENT}

I would like to thank the following people who in many ways contributed to this piece of work. First and foremost, I would like to thank Mr. Muhammad Afzal (The Principal of Lahore School of Nursing) who allowed me to do this study and guided me. I would thank to Sir Muhammad Hussain for being my preceptor and I would also thanks to Miss Iram Majeed, Miss Kousar Parveen and Mr. Muhammad Azhar for being the great inspiration for my work when I had no idea to perform a research work.

\section{REFERENCES}

Anjum, M. S., Srikanth, M. K., Reddy, P. P., Monica, M., Rao, K. Y., \& Sheetal, A. (2016). Reasons for smoking among the teenagers of age 14-17 years in Vikarabad town: a cross-sectional study. Journal of Indian Association of Public Health Dentistry, 14(1), 80. 
Bagchi, N. N., Ganguly, S., Pal, S., \& Chatterjee, S. (2014). A study on smoking and associated psychosocial factors among adolescent students in Kolkata, India. Indian journal of public health, 58(1), 50.

Bartwal, J., Awasthi, S., Rawat, C. M. S., \& Arya, A. (2014). Awareness and Pattern of Tobacco Use among the Medical Students of Government Medical College. Indian Journal of Community Health, 26(2), 155-159.

Gholap, P. R. (2015). Study the Harmfull Effect of Smoking among the Adult in the Rural Area of Nashik District. Int. J. Life. Sci. Scienti. Res, 2(4).

Health, U. D. o., \& Services, H. (2014). The health consequences of smoking-50 years of progress: a report of the Surgeon General. Atlanta, GA: US Department of Health and Human Services, Centers for Disease Control and Prevention, National Center for Chronic Disease Prevention and Health Promotion, Office on Smoking and Health, 17.

Kumar, B., Prakash, R., Prakash, K., \& Muthuvenkatacha1lam, S. (2013). Effectiveness of an Awareness Program about the Harmful Effects of Tobacco and Alcohol on Knowledge and Self Reported Practice of Adolescent Students Studying in a Selected School of Dehradun India. International Journal of Nursing Science, 3(3), 57-61.

Kumar, M. M., \& Nageshwar, V. (2018). Awareness On Ill Effects Of Tobacco Use Among College Students: A Review Based On Available Literature. International Journal Of Scientific Research, 7(8).

Mohanan, P., Swain, S., Sanah, N., Sharma, V., \& Ghosh, D. (2014). A study on the prevalence of alcohol consumption, tobacco use and sexual behaviour among adolescents in urban areas of the Udupi District, Karnataka, India. Sultan Qaboos University Medical Journal, 14(1), e104.

Palamar, J. J., Zhou, S., Sherman, S., \& Weitzman, M. (2014). Hookah use among US high school seniors. Pediatrics, peds. 2014-0538.

Rao, S., Aslam, S. K., Zaheer, S., \& Shafique, K. (2014). Anti-smoking initiatives and current smoking among 19,643 adolescents in South Asia: findings from the Global Youth Tobacco Survey. Harm reduction journal, 11(1), 8 .

Saqib, M. A. N., Rafique, I., Qureshi, H., Munir, M. A., Bashir, R., Arif, B. W., . . Bhatti, L. (2017). Burden of Tobacco in Pakistan: Findings From Global Adult Tobacco Survey 2014. Nicotine and Tobacco Research, 20(9), 1138-1143.

Shah, N., \& Siddiqui, S. (2015). An overview of smoking practices in Pakistan. Pakistan journal of medical sciences, 31(2), 467.

Siegel, R. L., Miller, K. D., \& Jemal, A. (2017). Cancer statistics, 2017. CA: a cancer journal for clinicians, 67(1), 7-30.

Singh, V., \& Gupta, R. (2006). Prevalence of tobacco use and awareness of risks among school children in Jaipur. JAPI, 54, 609-612.

Sinha, D. (2005). Gutka advertisement and smokeless tobacco use by adolescents in Sikkim, India. Indian $J$ Community Med, 30(1), 18-20.

Solomon, S. D., Wu, J., \& Gillam, L. D. (2017). Essential Echocardiography: A Companion to Braunwald's Heart Disease E-Book: Elsevier Health Sciences.

Tuppad, S. B. (2017). A Study to Evaluate the Effectiveness of Structured Teaching Program on Knowledge regarding Ill Effects of Smoking among Students of Government High School, Fort, Bangalore, India. Methodology, 19, 27.

WHO, W. H. O. (2015). WHO global report on trends in prevalence of tobacco smoking 2015: World Health Organization.

WHO, W. H. O. (2017). Noncommunicable diseases: progress monitor 2017.

Zheng, W., McLerran, D. F., Rolland, B. A., Fu, Z., Boffetta, P., He, J., . . . Irie, F. (2014). Burden of total and cause-specific mortality related to tobacco smoking among adults aged $\geq 45$ years in Asia: a pooled analysis of 21 cohorts. PLoS medicine, 11(4), e1001631. 


\section{NOTES:}

This section presents the outcomes of the study, Profile of the respondents and outcome of questionnaire regarding knowledge of tobacco use ill-effects and also represents the result of paired t-test comparison before and after intervention and results for objective of this study "To evaluate the Effectiveness of health teaching program about the knowledge of tobacco use ill-effects among high school students.

\begin{tabular}{|c|c|c|c|}
\hline \multicolumn{4}{|c|}{ Table No:1 } \\
\hline S\# & $\begin{array}{l}\text { Demographic } \\
\text { Characteristic }\end{array}$ & $\mathbf{N}$ & $\%$ \\
\hline & & 54 & $100 \%$ \\
\hline 1 & & \multicolumn{2}{|c|}{ Occupation of parents } \\
\hline & Service in private sector & 14 & $25.92 \%$ \\
\hline & $\begin{array}{l}\text { Service in government } \\
\text { sector }\end{array}$ & 15 & $27.77 \%$ \\
\hline & Business & 17 & $31.48 \%$ \\
\hline & Agriculture & 08 & $14,81 \%$ \\
\hline 2 & & \multicolumn{2}{|c|}{ History of Tobacco use in Family } \\
\hline & Yes & 16 & $29.1 \%$ \\
\hline & No & 36 & $69.1 \%$ \\
\hline 3 & & \multicolumn{2}{|c|}{ Recreational facility at home } \\
\hline & Television & 33 & $60 \%$ \\
\hline & $\begin{array}{l}\text { Magazines and } \\
\text { newspapers }\end{array}$ & 04 & $07 \%$ \\
\hline & internet & 06 & $10 \%$ \\
\hline & Play with peers & 11 & $20 \%$ \\
\hline 4 & & \multicolumn{2}{|c|}{ Previous knowledge regarding the ill-effects of tobacco } \\
\hline & Yes & 13 & $23.3 \%$ \\
\hline & No & 41 & $74.7 \%$ \\
\hline
\end{tabular}

According to this table total of 54 respondents participated in the study it also represents the demographic characteristics of participants this table this shows that about $31.48 \%$ of parents have their own business, $69.1 \%$ have no history of tobacco use in their family $60 \%$ have television as recreational facility at home and $74.7 \%$ have Previous knowledge regarding the ill-effects of tobacco.

\begin{tabular}{|l|l|l|l|l|l|}
\hline \multicolumn{7}{|c|}{ Table No: 2 Mean Percentages } & SE & N \\
\hline & Mean & Mean\% & SD & .37 & 54 \\
\hline Knowledge score Pre intervention & 14.37 & $41.05 \%$ & 2.72 & 2.01 & 54 \\
\hline Knowledge score Post intervention & 28.15 & $80.00 \%$ & 14.80 & & 5 \\
\hline
\end{tabular}




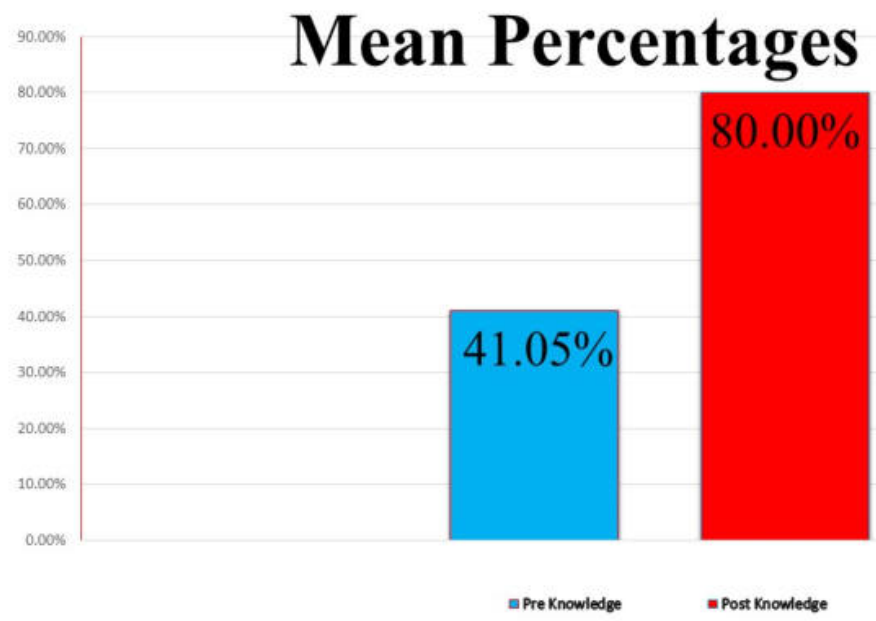

Following table and figure shows the mean, standard deviation, standard error of mean and mean percentages of pre-post score of knowledge and practice, illustrate that the knowledge and practice score mean improved in post intervention phase. That was 14.37 pretest knowledge and improved at 28.15 level in post intervention phase, similarly the practice mean also improved from $41.05 \%$ to $80.00 \%$ in post test phase.

\begin{tabular}{|c|c|c|c|c|}
\hline \multirow{2}{*}{\multicolumn{5}{|c|}{ Table No: 3}} \\
\hline & & & & \\
\hline \multirow[t]{2}{*}{ Variables } & \multicolumn{2}{|c|}{$\begin{array}{l}\text { Knowledge } \\
\text { pre-intervention }\end{array}$} & \multicolumn{2}{|c|}{$\begin{array}{l}\text { Knowledge } \\
\text { post-intervention }\end{array}$} \\
\hline & $\mathbf{N}$ & $\%$ & $\mathbf{N}$ & $\%$ \\
\hline $\begin{array}{l}\text { The age when tobacco use usually begins is } \\
\text { around 10years. }\end{array}$ & 05 & $9.25 \%$ & 34 & $62.96 \%$ \\
\hline $\begin{array}{l}\text { Tobacco use in adolescence is influenced by peer } \\
\text { group. }\end{array}$ & 39 & $72.22 \%$ & 49 & $90.74 \%$ \\
\hline $\begin{array}{l}\text { Smoking variety and smokeless variety are two } \\
\text { types of tobacco use. }\end{array}$ & 13 & $24.07 \%$ & 15 & $27.77 \%$ \\
\hline $\begin{array}{l}\text { Zarda, gutkha and snuff are the examples of } \\
\text { smoking variety. }\end{array}$ & 22 & $40.74 \%$ & 29 & $53.70 \%$ \\
\hline $\begin{array}{l}\text { One cigarette/beedi reduces seven minutes of } \\
\text { your life. }\end{array}$ & 06 & $11.11 \%$ & 41 & $75.92 \%$ \\
\hline Giving up tobacco use improves self-confidence. & 31 & $57.40 \%$ & 47 & $87.03 \%$ \\
\hline & & & & \\
\hline
\end{tabular}




\begin{tabular}{|c|c|c|c|c|c|c|c|c|}
\hline \multicolumn{9}{|c|}{ Table No: 4 Paired T-test } \\
\hline & \multicolumn{5}{|c|}{ Paired Differences } & \multirow[t]{3}{*}{$\mathrm{t}$} & \multirow[t]{3}{*}{$\mathrm{DF}$} & \multirow{3}{*}{$\begin{array}{l}\text { Sig. (2- } \\
\text { tailed) }\end{array}$} \\
\hline & \multirow[t]{2}{*}{ Mean } & \multirow[t]{2}{*}{ SD } & \multirow[t]{2}{*}{$\mathrm{SE}$} & \multicolumn{2}{|c|}{$\mathrm{C} \mathrm{I}$} & & & \\
\hline & & & & Lower & Upper & & & \\
\hline Pre-Post & -13.77 & 13.60 & 1.83 & -17.5 & -10.0 & 7.39 & 53 & .00 \\
\hline
\end{tabular}

Findings revealed that the mean post-test score was significantly higher than their mean pre-test score. The calculated' value $(\mathrm{t}=7.395 \mathrm{p}<0.005)$ was greater than the table value at 0.05 in all sections. Therefore, the null hypothesis (H0: There is no effectiveness of health teaching session about the knowledge of tobacco use illeffects among high school students) was rejected and alternate research hypothesis $\left(\mathbf{H}_{1}\right.$ : There is effectiveness of health teaching session about the knowledge of tobacco use ill-effects among high school students) was accepted. Hence it is concluded that there is significant gain in knowledge of students through health teaching program on tobacco use ill-effects.

\begin{tabular}{|c|r|r|r|r|r|r|}
\hline \multicolumn{8}{|c|}{ Tests of Normality } \\
\hline & \multicolumn{9}{|c|}{ Kolmogorov-Smirnov ${ }^{\mathrm{a}}$} & \multicolumn{3}{c|}{ Shapiro-Wilk } \\
\cline { 2 - 8 } & Statistic & df & \multicolumn{1}{c|}{ Sig. } & Statistic & \multicolumn{1}{c|}{ df } & \multicolumn{1}{c|}{ Sig. } \\
\hline Pre & .074 & 52 & $.200^{*}$ & .990 & 52 & .950 \\
\hline Post & .079 & 52 & $.200^{*}$ & .985 & 52 & .729 \\
\hline
\end{tabular}

Following table showed that according to Shapiro-wilk's test the ( $\mathrm{p}>.05)$ and the visual inspection of histogram, normal Q-Q plots and box plot showed that the score of knowledge and practice in pre and post phase were normally distributed.
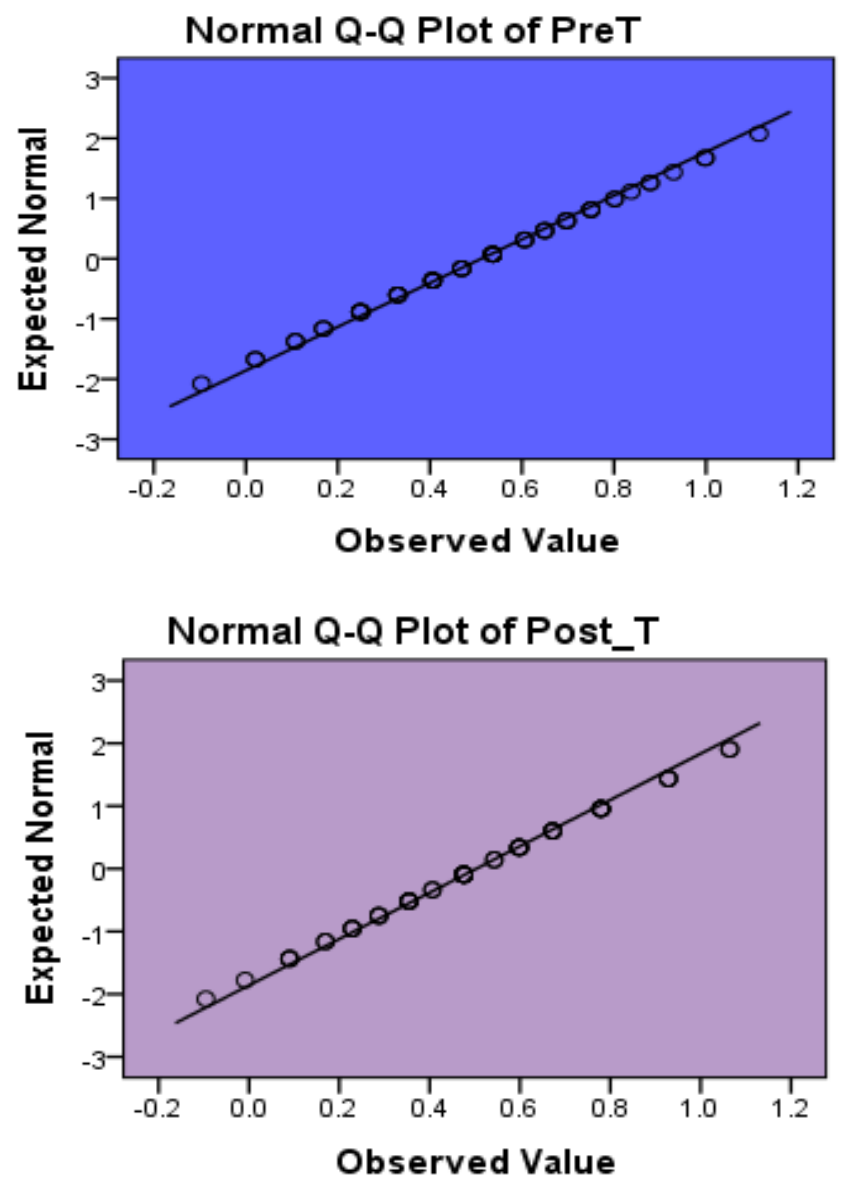